\title{
Molecular detection of Cryptosporidium parvum in chicken in Al-Diwaniya province
}

\author{
N.I. Jarad \\ Department of Veterinary Microbiology, College of Veterinary Medicine, University of Al-Qadisiyah, Iraq \\ Email: noor.jarad@qu.edu.iq
}

(Received October 2, 2019; Accepted November 19, 2019; Available online August 5, 2020)

\begin{abstract}
This study were conducted in Al-Diwaniya province, in south Iraq during the period from February to July 2019 to determine the rate of infection of Cryptosporidium parvum in domestic chicken, study the effect of some epidemiological factors such as sex and months on the rate of infection, addition to the molecular identification of Cryptococcus parvum by amplification HSP70 gene by conventional PCR. Number of collected fecal sample was 210 from domestic chicken and stained by Ziehl-Neelsen stain. The results of the microscopic examination showed that 108(51.4\%) out of 210 fecal samples were infected with Cryptosporidium spp. The statistical analysis founded no marked difference in prevalence of infection between sexes. Significant difference was recorded between infection rate during the months of the study and higher prevalence of infection rate was observed in March 11.9\%, while lowest infection rate was observed in July 5.23\%. and June 5.23\%. Genomic DNA was extracted from 108 fecal samples and HSP70 gene for $C$. parvum was amplified by PCR. PCR technique is showed that out of 108 fecal samples $21.3 \%$ were positive for Cryptosporidium parvum.
\end{abstract}

Keywords: Cryptosporidium parvum, Domestic chicken, PCR, Al-Diwaniya

DOI: $10.33899 /$ ijvs.2019.126159.1249, (2020, College of Veterinary Medicine, University of Mosul.

This is an open access article under the CC BY 4.0 license (http://creativecommons.org/licenses/by/4.0/).

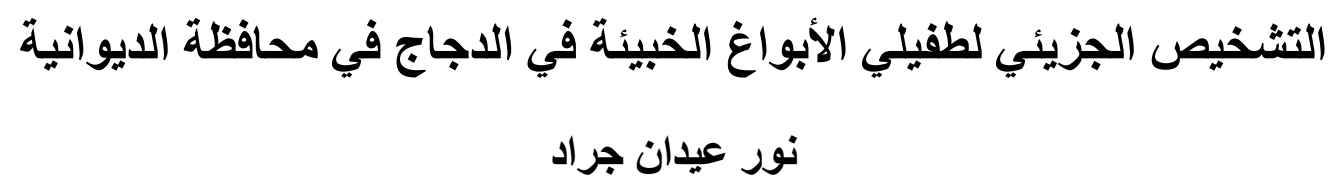

فرع الأحياء المجهرية البيطرية، كلية الطب البيطري، جامعة القادسية، العراق

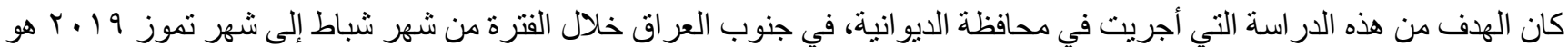

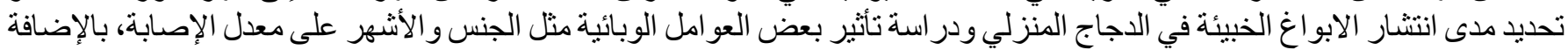

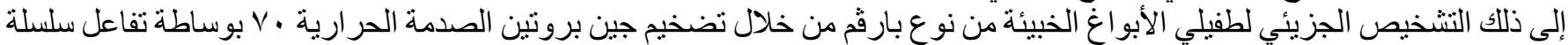

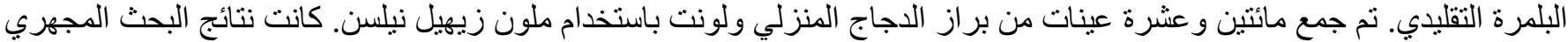

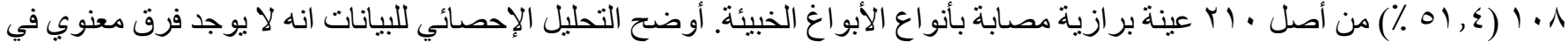

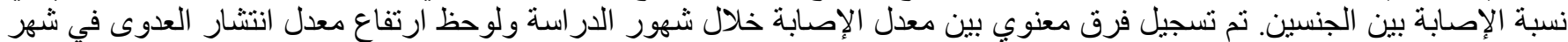

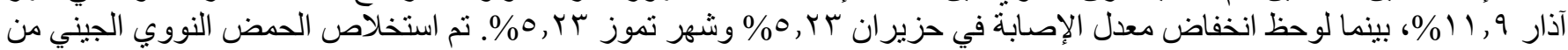

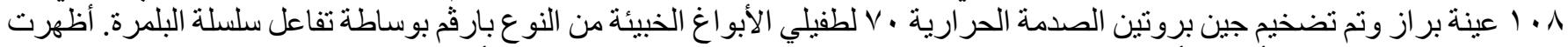

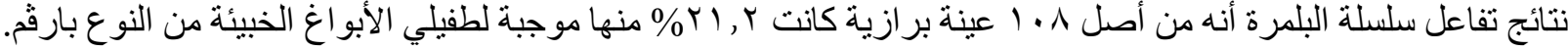




\section{Introduction}

Cryptosporidiosis is an infection caused by parasite which belongs to genus Cryptosporidium that parasitizes fish, amphibians, reptiles, birds and mammals (1). Cryptosporidium spp is parasite belonging to phylum Protozoa, Apicomplexa class Sporozoea subclass, Coccidia order, and family Cryptosporidiidae (1). Cryptosporidium spp have one life cycle which is completed in gut canal in one host. Several unique properties of Cryptosporidium are including lack specificity of infection of organs and hosts, it could resist antiparasitic drugs and it has high ability for autoinfection of the host cell (2). Life cycle of protozoan is done in the epithelial cells in the respiratory and gut canal especially in Bursa of Fabricius, but it less common in remain organs $(3,4)$. Cryptosporidium parvum is a coccidian parasite which invaded the intestinal of animals and humans, the diarrhea is most common clinical sign that occur due to C. parvum infection, and the infection could be chronic, and dangerous disease especially in immune compromised individuals $(5,6)$. Transmission of the parasite is done by faecal-oral way by taking contaminated water and food, it can infect young individuals (humans and animals); older animals can infect and shed the oocysts in the faeces which transfer the infection to others animals. The susceptibility and infectivity are varying among the hosts depending on many factors $(7,8)$. Infection of Cryptosporidium spp. causes inflammation in the mucosal tissues, associated with great numbers of macrophages and neutrophils in the infected tissue (9). Diagnosis of Cryptosporidium spp. is difficult due to their oocysts size when compared with another coccidian, therefore is difficult to observe, and the resemblance same to spores of yeast and fungi (10). Many of laboratory methods for diagnosis parasite infection have many limitations as acid fast stain or microscopic examination. The false-negative data are common in number of oocysts samples due to low sensitivity of the staining methods (11). Immunological methods used in the diagnosis of $C$. parvum like latex test (12), ELISA (13), IFAT (14) flow cytometry (15). Histological examination of intestinal biopsy with different stain is like eosin and hematoxylin, acid-fast stain and safranin-methylene blue also used in the diagnosis (16). Recently molecular technique used in the diagnosis, Polymerase chain reaction is modern technique can detection of Cryptosporidium spp. in high selectivity in all types of samples, as well as it used for genotyping by amplify suspect DNA thousands of times (17). The goal of present study was to determination what are more sensitive methods PCR methods or microscopic methods in diagnosis of Cryptosporidium parvum is done by using heat shock protein 70 (HSP70) gene that prepared from Cryptosporidium parvum.

\section{Materials and methods}

\section{Samples collections}

Fresh Two hundred and ten of domestic chicken (Gallus gallus domesticus) faecal samples were collected directly from rectum from several regions collected from several regions in Al-Diwanyia and kept in clean container labeled for date, animal age and sex, and then transferred to the Laboratory of parasite in College of Veterinary Medicine, Al-Qadisiya University, and to laboratory for genomic DNA extraction. Thirty-five faecal samples were processed and examined monthly.

\section{Microscopic examination by Ziehl-Neelsen stain}

Small quantity of fecal sample was taken and placed on a glass slide and mixed with adequate little physiological solution then left to dry for 11 minutes. All slides were fixed by immersing them in the concentrated methanol solution five minutes and left to dry at $25^{\circ} \mathrm{C}$. The slides were flooded with Carpal Fuchsin, was placed in oven at 61 degree for 11 - 15 minutes and rinsed off in tap water. Then slides were stained with a blue methanol dye for 2 minutes, washed with water and left to dry, after that examined by light microscope under oil immersion (18). The positive preserved at $-20 \mathrm{c}^{\circ}$ for molecular study.

\section{Extraction of DNA}

The genomic material was prepared by extraction and purifying from samples by kit called (stool DNA extraction), Bioneer Company, made in Korea). The extraction methods were done depend on company directions by using lysis protocol and Proteinase K. then, DNA was tested by Nanodrop apparatus and keep at $-20^{\circ} \mathrm{C}$.

\section{Polymerase Chain Reaction (PCR)}

The PCR reaction is done by using designed primer for Cryptosporidium parvum HSP70 gene, (GenBank: KC885897.1). The HSP70 forward primer AGG GTG AGA GAG CCA TGA CT and HSP70 reverse primer CAG TTT GGT TGT GCT CGA GC (Bioneer Company, Korea) with at 429 bp product size. The master mix was mixed by kit (AccuPower ${ }^{\circledR}$ PCR PreMix, Bioneer, Korea). The premix tube consists from dNTPs $250 \mu \mathrm{M}$, Taq polymerase enzyme, $\mathrm{KCl} 30 \mathrm{mM}$, Tris- $\mathrm{HCl} 10 \mathrm{mM}$, stabilizer, $\mathrm{MgCl}_{2} 1.5 \mathrm{mM}$ and ethidium bromide stain. The master mix was prepared depend on kit directions which consist from DNA sample $5 \mathrm{uL}$, and forward primer $01.5 \mathrm{ul}$, and reverse primer $1.5 \mathrm{ul}$, and completing contains by water (20ul) and then mixed by vortex. All time of reaction was done in thermocycler device (Mygene Bioneer Company, Korea) and setting the apparatus as the initial denaturation $95^{\circ} \mathrm{C}$ for five minute; second stage (denaturation) 30 cycles at $95^{\circ} \mathrm{C}$ for thirty second, the annealing stage $60^{\circ} \mathrm{C}$ for thirty seconds, the extension stage $72^{\circ} \mathrm{C}$ for sixty seconds, the final extension 
$72^{\circ} \mathrm{C}$ for 5 minutes, the products were tested by electrophoresis and then the sample is stained with ethidium bromide and the UV lighter is used for watching the bands.

\section{Results}

\section{Microscopic result}

The infection with cryptosporidium spp was detected in $108(51.4 \%)$ out of 210 faecal samples examined using light microscopic, the infection rate was $42 \%$. The oocyst is round in shape, length $7-5.2 \mu \mathrm{m}$, width 4.5-4.8 $\mu \mathrm{m}$ (Figure 1).

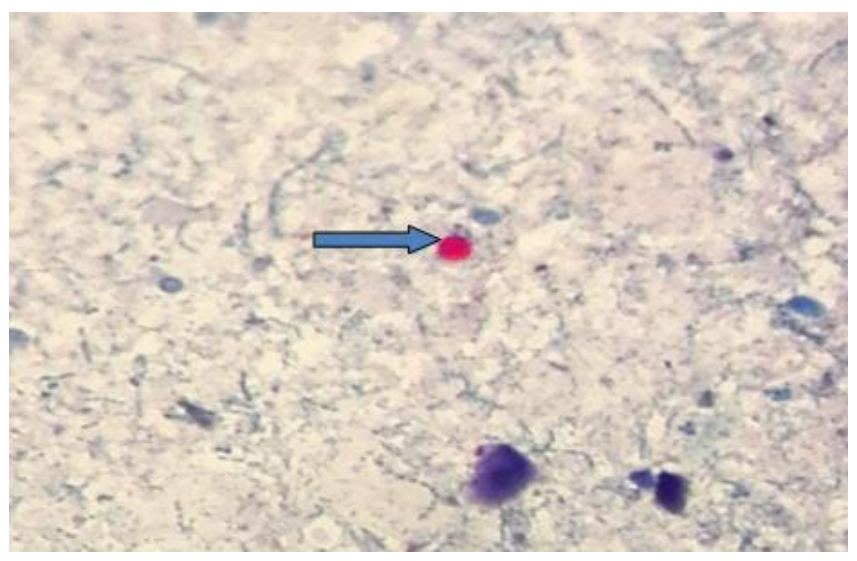

Figure 1: Oocyst of Cryptosporidium spp.

\section{Infection rate of Cryptosporidium spp. in relation to sex}

In regard to sex, no marked effect in total prevalence between males $25.23 \%$ and females $26.19 \%$ (Table 1). No significant differences were found between prevalence according to sex.

Table 1: The prevalence of Cryptosporidium spp. according to sex

\begin{tabular}{lccc}
\hline Sex & Total No. & Positive & Percentage (\%) \\
\hline Males & 98 & 53 & 25.23 \\
Females & 112 & 55 & 26.19 \\
\hline Total & 210 & 108 & 51.4 \\
\hline $\mathrm{X}^{2}$ & & 0.518 & \\
P-value & & 0.47169 & \\
\hline
\end{tabular}

\section{Infection rate of Cryptosporidium spp in relation to months}

Monthly examination of 35 faecal sample from February to July 2019 is shown in (Table 2). The high prevalence rate was in March $11.9 \%$ and February $11.4 \%$ while lower prevalence was in June $5.23 \%$ and July $5.23 \%$. significant differences were found between prevalence according to months.
Table 2: Infection rate of Cryptosporidum spp according to months

\begin{tabular}{lccc}
\hline Sex & Total No. & Positive & Percentage (\%) \\
\hline February & 35 & 24 & 11.4 \\
March & 35 & 25 & 11.9 \\
April & 35 & 21 & 10 \\
May & 35 & 16 & 7.61 \\
June & 35 & 11 & 5.23 \\
July & 35 & 11 & 5.23 \\
Total & 210 & 108 & 51.4 \\
$\mathrm{X}^{2}$ & & 22.418 & \\
P-value & & 0.000435 & \\
\hline
\end{tabular}

\section{Molecular result}

The overall prevalence of Cryptosporidium parvum was $21.3 \%$ out of 108 samples was as estimated using HSP70 gene . Figure(2) .

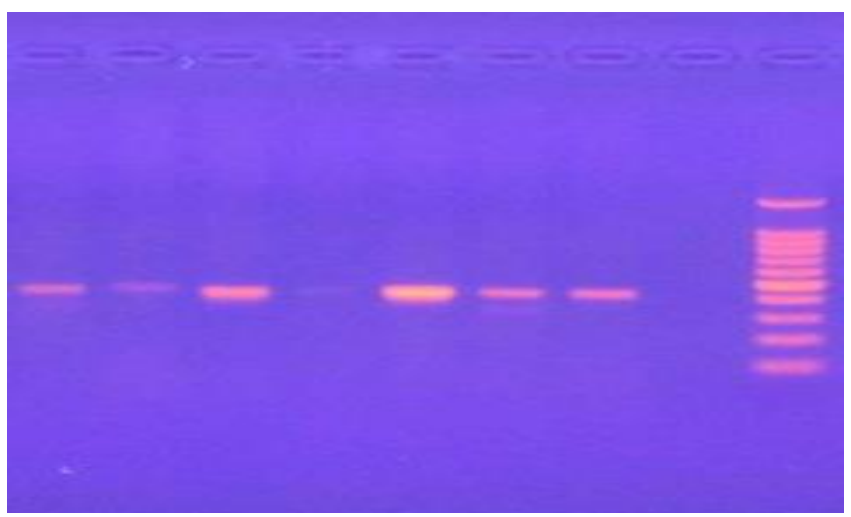

Figure 2: Bands under UV lighter which showed the gene HSP70 product, Line indicate to DNA marker, the Lanes 18 indicate to the positive and negative samples at $429 \mathrm{bp}$ after use electrophoresis.

\section{Discussion}

In Al-Diwaniya province, south Iraq few reports are done about this subject in domestic chicken. The total percentage of Cryptosporidium spp. infection was $51.4 \%$ in chicken by staining with acid-fast staining. Our results were in resemblance with Al- Zubaidi (19) in Al-diwaniya and Baroudi (20) in Algeria, while were less than that in Brazil by Bomfim (21). The result of this study is disagreement with some of studies which recorded a low prevalence rate as Wang (22) which recorded $1.6 \%$ in China and Kichou (23) who found the infection of $24 \%$ in chickens in Morocco. The differences in the rates may be occurring due to using of many different methods and the sample taken from different area, differences in management practices, different species of birds and hygienic conditions. Concerning the sex, our 
results showed that the difference was not statistically significant. A similar result was recorded in previous studies by Al-Zubaidi (24-26). They confirmed that both sexes are equally affected by the factors lead to infection and that the sex of the host does not play an important role in the infection with this disease. Other studies have been conducted with other host recorded no statistically significant between males and females as study by Casemore (27). In general, it could be said that these differences in the relationship of the host sex with parasite is relative since it varies female or the opposite, but it cannot confirm the existence of sex-related factors affect the parasitic infection and make it tends to infect a specific host sex without the other, we could not neglect the increase of infection during poor immune status during the egg laying period in females.

According to the months, the present study reveals significant differences between prevalence of infection. The high prevalence rate was in March $11.90 \%$ and February $11.42 \%$ and lower prevalence was in June $5.23 \%$ and July $5.23 \%$. The cold months prolong the survival of the oocyst in the soil, due to optimum temperature and humidity for development of parasites oocyst. Our result was similar to the study in Al-Diwaniya province conducted by Al-Zubaidi (19) who recorded the higher prevalence was in March $87.5 \%$, while lowest infection rate was observed in July $27.8 \%$. The current study disagrees with result of study by Bamaiyi (28) which recorded the high rate in dry months because the spread of oocysts with dust particles.

The molecular characterization of animal could be used to investigate the possible zoonosis of Cryptosporidium spp. and genotyping (29). In this study, PCR with HSP70 target gene s was used for the identification of $C$. parvum isolated form 210 faecal samples of domestic chicken in Al-Diwaniya province. HSP70 structure in humans is likely to $72 \%$ with drosophilae (30), HSP70 of the chicken is $71 \%$ similar to drosophila and $80 \%$ similar to the gene in the human (31).

The results revealed that $23(21.3 \%)$ of 210 faecal samples were contain C. parvum infection. the result was in agreement with other study in Al-Diwaniya province conducted by AL- Zubaidi (19) which recorded C. parvum in domestic chicken using 18S rRNA gene for molecular detection of this parasite in domestic chicken. C. parvum rate in the present study was higher than that reported in Germany $3.2 \%$ by Helmy (32) out of 158 samples. The result of this study was in agreement with other study conducted by Berrilli (33) in Italy.

\section{Conclusion}

For diagnosis of C. parvum, this study clearly indicated that a PCR method using the sequences of HSP70 gene to diagnosis of $C$. parvum.

\section{Acknowledgements}

The authors wish to thank the College of Veterinary Medicine, University of Al-Qadisiya for providing the facilities needed.

\section{Conflict of interest}

The authors declare that there are no conflicts of interest regarding the publication of this manuscript.

\section{References}

1. Thompson, R.A. Fayer R, Xiao L, (eds). Cryptosporidium and Cryptosporidiosis. ParasitesVectors.2008; 1, 47.https://doi.org/10.118 6/1756-3305-1-47

2. Omoruyi BE, Nwodo UU, Udem CS, Okonkwo FO. Comparative diagnostic techniques for Cryptosporidium infection. Molecules. 2014;19:2674-2683. doi: 10. 3390 /molecules 19022674.

3. Barta JR, Thompson RC. What is Cryptosporidium? Reappraising its biology and phylogenetic affinities. Trends Parasitol. 2006;22(10):463468. Doi: 10.1016/j.pt.2006.08.001

4. Valigurova A, Jirku M, Koudela B, Gelnar M, Modry D, Slapeta J. Cryptosporidia: Epicellular parasites embraced by the host cell membrane. Int J Parasitol. 2008;38(8-9):913-922. Doi: 10.1016/j.ijpara.2007.11.003

5. Santin M. Clinical and subclinical infections with cryptosporidium in $\begin{array}{lllll}\text { animals. } & \mathrm{N} & \mathrm{Z} & \text { Vet } & \text { J.2013;61(1):1-10. Doi: }\end{array}$ $10.1080 / 00480169.2012 .731681$

6. Voelz k, May R. Cryptococcal interactions with the host immune system. 2010;9(6):835-46. Doi: 10.1128/EC.00039-10

7. Borad A, Ward H. Human immune responses in cryptosporidiosis. Future Microbiol. 2010;5:507-519. Doi: 10.2217/fmb.09.128

8. Yang YL, Buck GA, Widmer G. Cell sorting-assisted microarray profiling of host cell response to Cryptosporidium parvum infection. Infect Immun. 2010;78:1040-1048. Doi: 10.1128/IAI.01009-09.

9. Manyazewal A, Francesca S, Pal M, Gezahegn M, Tesfaye M, Lucy M, Teklu W, Getachew T. Prevalence, risk factors and molecular characterization of Cryptosporidium infection in cattle in Addis Ababa and its environs, Ethiopia Vet Parasitol Reg Stud Reports. 2018;13:7984. doi: 10.1016/j.vprsr.2018.03.005.

10. Alseady HH, Kawan MH. Prevalence and molecular identification of Cryptosporidium spp in cattle in Baghdad province, Iraq. Iraqi J Vet Sci. 2019;33:389-394. DOI: 10.33899/ijvs.2019.163084.

11. Jex AR, Smith HV, Monis PT, Campbell BE, Gasser RB. Cryptosporidium - biotechnological advances in the detection, diagnosis and analysis of genetic variation. Biotechnol Adv. 2008;26(4):304-317. Doi: 10.1016/j.biotechadv.2008.02.003

12. Casemore DP. Laboratory methods for diagnosis cryptosporidium. J Clin Pathol. 1991;44:445-450. Doi: 10.4103/tp.TP-34-17

13. Lazo AO, Barriga O, Redman DR, Bech NS. Identification by transfer blot antigens reactive in the enzyme-linked immunosorbant assay (ELISA) in rabbits immunized and calf infected with Cryptosporidium spp. J Vet Parasitol. 1986;21:151-163. Doi: 10.1016/03044017(86)90062-2

14. Balatbat AB, Jordan GW, Tang UJ, Josephsilva JR. Detection of cryptosporidium DNA in human fecal by nested PCR. J Clin Microbiol. 1996;34(7):1769-1772.

15. Mahfouz ME, Mira N, Amer S. Prevalence and genotyping of Cryptosporidium spp. in farm animals in Egypt. J Vet Med Sci. 2014;76(12):1569-1575. doi: 10.1292/jvms.14-0272

16. Abdou AG, Harba MN, Afifi AF, Elnaidany NF. Assessment of Cryptosporidium parvum infection immunocompetent and immunocompromised mice and its role in triggering intestinal 
dysplasia. Inter J Infect Dis. 2013;17:593-600. Doi: 10.1016/j.ijid.2012.11.023

17. Kaushik K, Khurana S, Wanchu A, Malla N. Evaluation of staining techniques, antigen detection and nested PCR for the diagnosis of cryptosporidiosis in HIV seropositive and seronegative patients. Acta Trop. 2008;107:1-7. Doi: 10.1016/j.actatropica

18. Helmy YA. Epidemiological investigations on the public health significance of Cryptosporidium parasites in livestock and people in the Ismailia Canal Zone of Egypt [PhD dissertation]. Freie Universität Berlin, Germany; 2014. 77 p. doi.org/10.1016/j.vetpar.2012.12.015.

19. Al- Zubaidi IAM. Investigation for Cryptosporidiosis in some species of wild and domestic birds and study of histopathological changes which combined of it . Al-Qadisiyah Journal of pure science;22(4) 6778. Doi:/1029350/Jobs.

20. Baroudi, D, Khelef D, Goucem R, Adjou KT, Adamu H, Zhang H, Xiao L. Common occurrence of zoonotic pathogen Cryptosporidium meleagridis in broiler chickens and turkey in Algeria. J Vet Parasitol. 2013;196:334-340. Doi: 10.1016/j.vetpar.2013.02.022.

21. Bomfim TC, Gomes RS, Huber F, Couto MC. The importance of poultry in environmental dissemination of Cryptosporidium spp. J Vet Sci. 2013;7:12-17. Doi: 10.2174/1874318801307010012.

22. Wang R, Jian F, Sun Y, Hu Q, Zhu J, Wang F, Ning C, Zhang L, Xiao L. Large-scale survey of Cryptosporidium spp. J Avian Pathol. 2013;39(6):447- 451. Doi: 10.1080/03079457.2010.518314.

23. Kichou F, Saghir F, El-Hamidi M. Infection naturelle a Cryptosporidium sp. chez le poulet de chair au Maroc. Avian Pathol. 1996;25:103-111. Doi/pdf/10.1080/03079459608419124.

24. Ryan UM. Cryptosporidium in birds, fish and amphibians. J Ex Parasitol. 2010;124:113-120. Doi: 10.1016/j.exppara.2009.02.002.

25. Wang R, Meng Q, Zhu J, Dong S, Changshen N, Jinfeng Z, Longxian Z, Xiao L. Prevalence of Cryptosporidium baileyi in ostriches (Struthio camelus) in Zhengzhou, China. J Vet Parasitol. 2011;175(1-2):151-154. Doi: 10.1016/j.vetpar.2010.10.005.
26. Bamaiyi PH, Umoh JU, Abdu PA, Lawal IA. The prevalence of cryptosporidium oocysts in birds in Zaria, Nigeria. J Res Sci Tech. 2013;2(2):52-59. DOI: 10.13140/RG.2.1.2865.6082.

27. Casemore DP. Human cryptosporidiosis: Recent advances in infection. J Parasitol. 1998;3:209-236. Doi: 10.1097/QCO.0b013e328357e569.

28. Bamaiyi PH, Umoh JU, Abdu PA, Lawal IA. The prevalence of cryptosporidium oocysts in birds in Zaria, Nigeria. J Res Sci Tech. 2013;2(2):52-59. Doi: 10.33736/bjrst.278.2013.

29. Xiao L, Fayer R. Molecular characterization of species and genotypes of Cryptosporidium and Giardia and assessment of zoonotic transmission. Int J Parasitol. 2008;38:1239-55. Doi: 10.1016/j.ijpara.2008.03.006.

30. Hunt C, Morimoto RI. Conserved features of eukaryotic hsp70 genes revealed by comparison with the nucleotide sequence of human hsp70. Proc Natl Acad Sci. 1985;82:6455-6459. Doi:10.1073/pnas.82.19.6455.

31. Morimoto RI, Hunt C, Huang SY, Berg KL. Organization, nucleotide sequence, and transcription of the chicken HSP70 gene. J Biol Chem. 1986;261:12692-12699. doi: 10.1006/jipa.1986.4686.

32. Helmy YA, KruĖcken J, Abdelwhab ES, Von Samson HG, Hafez HM. Molecular diagnosis and characterization of Cryptosporidium spp. in turkeys and chickens in Germany reveals evidence for previously undetected parasite species. PLoS ONE. 2017;12(6):e0177150. Doi: doi.org/10.1371/journal.pone.0177150.

33. Berrilli F, D'Alfonso R, Giangaspero A, Marangi M, Brandonisioe O, Kaborec Y, Glec C, Cianfanelli C, Laurob R, Di Cavea D. Giardia duodenalis genotypes and Cryptosporidium species in humans and domestic animals in Cote d'Ivoire: occurrence and evidence for environmental contamination. Transact Royal Soc Trop Med Hyg. 2012;106:191-195. Doi: doi.org/10.1016/j.trstmh.2011.12.005 